\title{
Reflexões sobre a educação profissional e tecnológica a partir da confecção de um
}

\section{fanzine}

\section{Reflections on professional and technological education based on the creation of a fanzine}

Reflexiones sobre la formación profesional y tecnológica a partir de la creación de un fanzine

\section{Resumo}

Este artigo tem como objetivo documentar uma atividade didático-pedagógica realizada pelos discentes em uma aula do Mestrado em Educação Profissional e Tecnológica do Instituto Federal de Santa Catarina. A turma dividida em grupos produziu fanzines representando uma profunda reflexão acerca dos conteúdos estudados durante o semestre na disciplina de Bases Conceituais para a Educação Profissional e Tecnológica ministrada pelo Professor Doutor Adriano Larentes da Silva. O fanzine produzido pelo grupo foi feito com recortes de revistas e jornais e tratou de temas referentes à dualidade estrutural na educação, à influência dos organismos multilaterais nas políticas educacionais, aos conflitos entre capital e trabalho e à reforma do Ensino Médio. Cada seção do artigo traz a foto de uma página do fanzine produzido e o referencial teórico que deu suporte a tais reflexões.

Palavras-chave: Fanzine; Ensino; Educação profissional; Política educacional.

\begin{abstract}
This article aims to document a didactic-pedagogical activity carried out by students in a Master's in Professional and Technological Education class at the Federal Institute of Santa Catarina. The class divided into groups produced fanzines, representing a deep reflection on the contents studied during the semester in the discipline of Conceptual Bases for Professional and Technological Education, taught by Professor Dr Adriano Larentes da Silva. The fanzine produced by the group was made with clippings from magazines and newspapers and dealt with themes related to the structural duality in education, the influence of multilateral organizations on educational policies, the conflicts between capital and work and the reform of secondary education. Each section of the article brings a photo of a page from the fanzine produced and the theoretical framework that supported such reflections.
\end{abstract}

Keywords: Fanzine; Teaching; Professional education; Educational policy.

\section{Resumen}

Este artículo tiene como objetivo documentar una actividad didáctico-pedagógica que realizan los estudiantes de una Maestría en Educación Profesional y Tecnológica del Instituto Federal de Santa Catarina. El grupo dividido en grupos produjo fanzines, que representan una profunda reflexión sobre los contenidos estudiados durante el semestre en la disciplina de Bases Conceptuales para la Educación Profesional y Tecnológica, impartida por el profesor Dr. Adriano Larentes da Silva. El fanzine producido por el grupo se realizó con recortes de revistas y periódicos y abordó temas relacionados con la dualidad estructural en la educación, la influencia de los organismos multilaterales en las políticas educativas, los conflictos entre capital y trabajo y la reforma de la educación secundaria. Cada sección del artículo trae una foto de una página del fanzine producido y el marco teórico que sustenta tales reflexiones.

Palabras clave: Fanzine; Enseñanza; Educación profesional; Política educativa. 


\section{Introdução}

A proposta deste artigo surgiu após uma atividade didático-pedagógica realizada na disciplina de Bases Conceituais para a Educação Profissional e Tecnológica, que integra o currículo do Mestrado em Educação Profissional e Tecnológica ofertado pelo Instituto Federal de Santa Catarina, ministrada pelo Professor Doutor Adriano Larentes da Silva. Durante a última aula da disciplina, a turma de 24 mestrandos foi dividida em grupos de quatro integrantes a fim de produzir um fanzine, cujo objetivo era o de expressar uma reflexão e síntese de todos os conteúdos vistos durante o semestre.

Fanzines são publicações alternativas, geralmente produzidos por admiradores de determinada arte, personalidade, hobby, etc., livres de censura e que buscam se expressar ao criar e divulgar conteúdos que não são publicados na grande mídia, ou que carregam um ponto de vista que diverge dos meios tradicionais de comunicação. O conteúdo do fanzine traz a visão de seus autores os quais devem se encarregar de todo o processo de produção desde a concepção da ideia até a coleta de informações, montagem e distribuição (Magalhães, 1993).

Inspirado a expressar os conhecimentos adquiridos ao longo do semestre de forma crítica por meio desse tipo de material, o grupo teve um período de quatro horas para conceber a ideia, planejar e produzir o fanzine. Foram feitos recortes em revistas e jornais que tinham relação com os temas dos textos estudados em sala de aula e com eles uma colagem, em forma de revista com quatro páginas de conteúdo.

Diante disso, o presente artigo apresenta o seguinte problema: a utilização do fanzine como recurso didático, na síntese final de uma unidade curricular de mestrado, é capaz de explorar a criatividade e capacidade crítica dos estudantes? Já que este recurso não apenas prioriza a crítica, a informação e a reflexão, mas também permite ser produzida e publicada artesanalmente, de forma alternativa e amadora (Magalhães, 1993).

O objetivo geral desta pesquisa é documentar uma atividade didático-pedagógica que tem como proposta estimular a capacidade crítica e reflexiva por meio da confecção de um fanzine. Busca-se atingir esse objetivo geral por intermédio dos seguintes objetivos específicos: a) identificar o trabalho elaborado pelos estudantes com a finalidade de sintetizar os conceitos dos autores trabalhados durante o semestre; b) analisar a crítica representada por textos, recortes e imagens do fanzine com o intuito de esclarecer a intencionalidade dos mestrandos.

A primeira página do fanzine foi inspirada nos artigos de Shiroma (2011) e de Shiroma, Campos e Garcia (2005). No primeiro texto, Shiroma (2011) aborda a influência que os organismos internacionais como a UNESCO e o Banco Mundial exercem na produção das políticas educacionais dos países da América Latina. Os argumentos presentes nos documentos desses Organismos Multilaterais são encontrados em discursos de professores e gestores educacionais e as prescrições são rapidamente difundidas, "tornando-se slogans nos discursos sobre educação" (Shiroma, 2011, p. 17). Para compreender essa "hegemonia discursiva", Shiroma et al. (2005) mostram caminhos para decifrar textos sobre política e como determinados termos difundidos em diversos documentos estão carregados de significado e levam à homogeneização das políticas educacionais em nível mundial.

A segunda e a terceira página do fanzine são resultado de uma reflexão acerca da tendência à dominação do capital na educação, com vistas a oferecer uma meia-educação aos pobres (Mendes, 1983) que ajustem suas subjetividades para atender às necessidades do modo de produção dominante (Gramsci apud Kuenzer \& Grabowski, 2016). Também é feita uma crítica acerca da Reforma do Ensino Médio em curso no governo Temer que tende ao estabelecimento de itinerários formativos específicos e profissionalização precoce com foco no mercado (Moura \& Lima, 2017), a qual se afasta do Ensino Médio Integrado que propõe a formação humana e omnilateral.

Finalmente, a última página do fanzine trata do Brasil dividido entre a classe dominante e a classe trabalhadora e como essa divisão produtora de profundas desigualdades na sociedade brasileira se expressa na educação por meio da dualidade estrutural que apresenta maior poder explicativo "a partir do ensino médio, e em especial na educação profissional” (Kuenzer \& Grabowski, 2016, p. 24). 


\section{Metodologia}

Este trabalho é fruto da leitura crítica do referencial teórico previamente selecionado a partir de levantamento bibliográfico realizado pelo Professor Dr Adriano Larentes da Silva, responsável pela disciplina de Bases Conceituais para a Educação Profissional e Tecnológica, do Mestrado Profissional em Educação Profissional e Tecnológica, ministrada no IFSC. De acordo com Gil (2008, p. 50), "a pesquisa bibliográfica é desenvolvida a partir de material já elaborado, constituído principalmente de livros e artigos científicos".

A leitura crítica, para Freire e Macedo (1987), implica em perceber a relação entre texto e contexto, uma vez que a leitura não consiste meramente na decodificação da palavra escrita ou da língua, mas é precedida e está entrelaçada com o conhecimento do mundo. A partir, então, da leitura crítica dos textos propostos, os autores deste artigo puderam criar o fanzine e desenvolver as reflexões apresentadas neste artigo. As reflexões que deram origem ao fanzine serão documentadas na próxima seção deste artigo, trazendo cada tópico a foto de uma página do fanzine e seus respectivos referenciais teóricos.

\section{O Fanzine e as Reflexões}

A produção de políticas educacionais é um processo complexo, em que interagem variados atores em um campo de disputas de interesses e projetos. Nesse aspecto, os estudos de Shiroma et al. (2005) e Shiroma (2011) colaboram para o entendimento dos intrincados mecanismos utilizados na implementação das políticas. Os organismos multilaterais assumiram a centralidade na produção das reformas educacionais, utilizando discursos e narrativas próprias, bem como de redes sociais na consecução de seus objetivos.

As reformas educacionais do final do século XX promoveram uma homogeneização mundial das políticas educacionais. Relatórios publicados nos Estados Unidos e Inglaterra, no início da década de 1980, iniciaram uma série de reformas em vários países. Nesse processo, organismos multilaterais como o Banco Mundial, a Organização das Nações Unidas para a Educação, a Ciência e a Cultura (UNESCO), a Organização para a Cooperação e Desenvolvimento Econômico (OCDE), o Programa das Nações Unidas para o Desenvolvimento (PNUD) e outros, produziram a reforma - com documentos que prescreviam orientações - , bem como a justificavam por meio de seu discurso:

\footnotetext{
"As recomendações presentes nos documentos de política educacional amplamente divulgados por meios impressos e digitais não são prontamente assimiláveis ou aplicáveis. Sua implementação exige que sejam traduzidas, interpretadas, adaptadas de acordo com as vicissitudes e os jogos políticos que configuram o campo da educação em cada país, região, localidade; tal processo implica, de certo modo, uma reescritura das prescrições, o que coloca para os estudiosos a tarefa de compreender a racionalidade que os informa e que, muitas vezes, parece contraditória, fomentando medidas que aparentam ir em direção contrária ao que propõem”. (Shiroma et al., 2005, p. 430-431)
}

Fica clara a complexidade do processo, envolto por várias nuances e quão necessários são os aportes teóricometodológicos para compreender as reformas. O discurso é texto, é prática discursiva e é prática social. A hegemonia de um grupo depende, em parte, de sua capacidade de gerar práticas discursivas e ordens de discurso que a sustentem, sendo assim, o discurso em si se apresenta como uma esfera da hegemonia (Resende \& Ramalho, 2006).

Desde meados dos anos 1990 houve uma transformação no discurso dos organismos multilaterais, mudando a ênfase de uma esfera economicista para uma abordagem mais humanitária. Colabora para isso a adoção de um vocabulário específico, que busca legitimar e justificar suas medidas. Segundo Shiroma et al. (2005), "a vulgarização do 'vocabulário da reforma' pode ser considerada uma estratégia de legitimação eficaz na medida em que consegue 'colonizar' o discurso, o pensamento educacional e se espalhar no cotidiano como demanda imprescindível da "modernidade"' (p. 429). Dessa forma, certas palavrasfetiche se incorporam no vocabulário não só de educadores, mas da sociedade em geral que, alimentada pelo discurso midiático e do mercado editorial, passa a aceitar e/ou clamar por demandas que nem sempre refletem seus verdadeiros interesses. 
Na efetivação das reformas, um dos elementos chave a se entender são as mediações entre os sujeitos. Planos de educação, recomendações e textos oficiais não são simplesmente transmitidos de cima para baixo e sua produção e circulação passa por grupos que influenciam o governo e a sociedade, agrupados em redes políticas e sociais. Para Shiroma (2011) “redes sociais são definidas como um conjunto de pessoas e/ou organizações que se agregam com interesse comum, contribuem para a produção e disseminação de informações, criam canais de comunicação e estimulam a participação da sociedade” (p. 18). Há, na América Latina, redes sociais que contam com o apoio de organismos multilaterais, tais como o Programa Regional da Reforma Educativa na América Latina (PREAL), o Centro Interamericano para o Desenvolvimento do Conhecimento em Formação Profissional da OIT (CINTERFOR/OIT), o Centro Internacional para a Educação e Formação Técnica e Profissional (UNEVOC) e a Rede Latino-Americana de Organizações da Sociedade Civil para a Educação (REDUCA), entre outras.

Essas redes desenvolvem uma série de atividades e, entre seus integrantes, contam com pessoas e organizações com influência e trânsito na política nacional. Tendo sempre em vista as interconexões entre o global e o local, cabe notar que muitos desses integrantes mantêm institutos, fundações, consultorias, editoras e outros aparatos que capilarizam a difusão das ideias e dos discursos da reforma.

Figura 1 - Primeira página do fanzine.

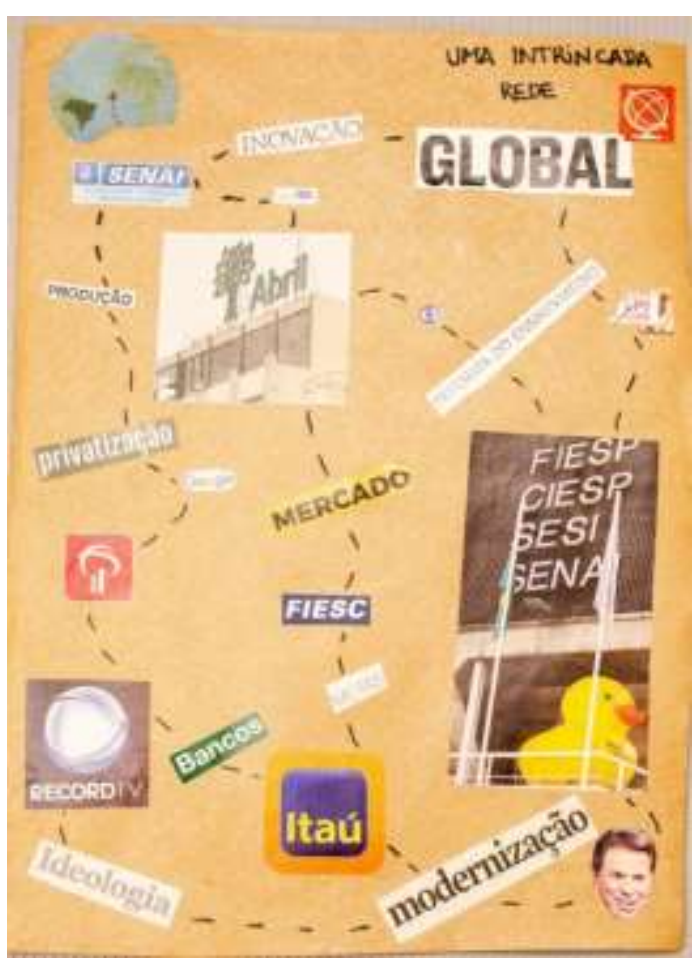

Fonte: Autores (2018).

O fanzine inicia trazendo os conceitos de Shiroma et al. (2005) e Shiroma (2011), em especial o de redes sociais. Intitulado "Uma intrincada rede global”, nele pode-se ver algumas das palavras-fetiche que compõem o 'vocabulário da reforma', tais como 'inovação', 'privatização', 'modernização', 'mercado', 'metas’ e outras. Em sua tarefa de compreender os discursos, Shiroma et al. (2005) questionam: “por exemplo, quando se afirma que é preciso melhorar a qualidade da educação: melhor ou qualidade dizem respeito a que conjunto de valores? Melhor dentro de que concepção de educação?” (p. 438). Os termos não são neutros nem genéricos e envolvem juízos de valores. Nessa rede, tais palavras se articulam com alguns dos atores que propagam o ideário da reforma: os bancos (com suas fundações educacionais e institutos culturais), as entidades empresariais (FIESP, FIESC, SESI, SENAI) e a mídia (Globo, Record, Google, Grupo Abril e outros). 
No início da segunda página do referido fanzine, os autores alertam em vermelho e caixa alta: "Não se engane!” O aviso remete às promessas que permeiam as reformas educacionais desde a década de 1930 no país, que mudou do modelo produtivo agrário-exportador para o urbano industrial. Ciavatta e Ramos (2012) afirmam que "a perspectiva de um futuro vitorioso e democrático transforma as reformas em lugar de luta social”' (p. 15). Esse campo de disputa que emerge no Brasil tem em seu cerne o empresariado, dada a necessidade de mão de obra com conhecimentos específicos além do interesse do setor privado pela partilha dos recursos destinados à educação, e as organizações da sociedade civil em defesa da universalidade do ensino básico, já que a classe pobre e trabalhadora tinha na educação pública a oportunidade ímpar para ter um nível mínimo de escolarização.

Figura 2 - Segunda e terceira páginas do fanzine.

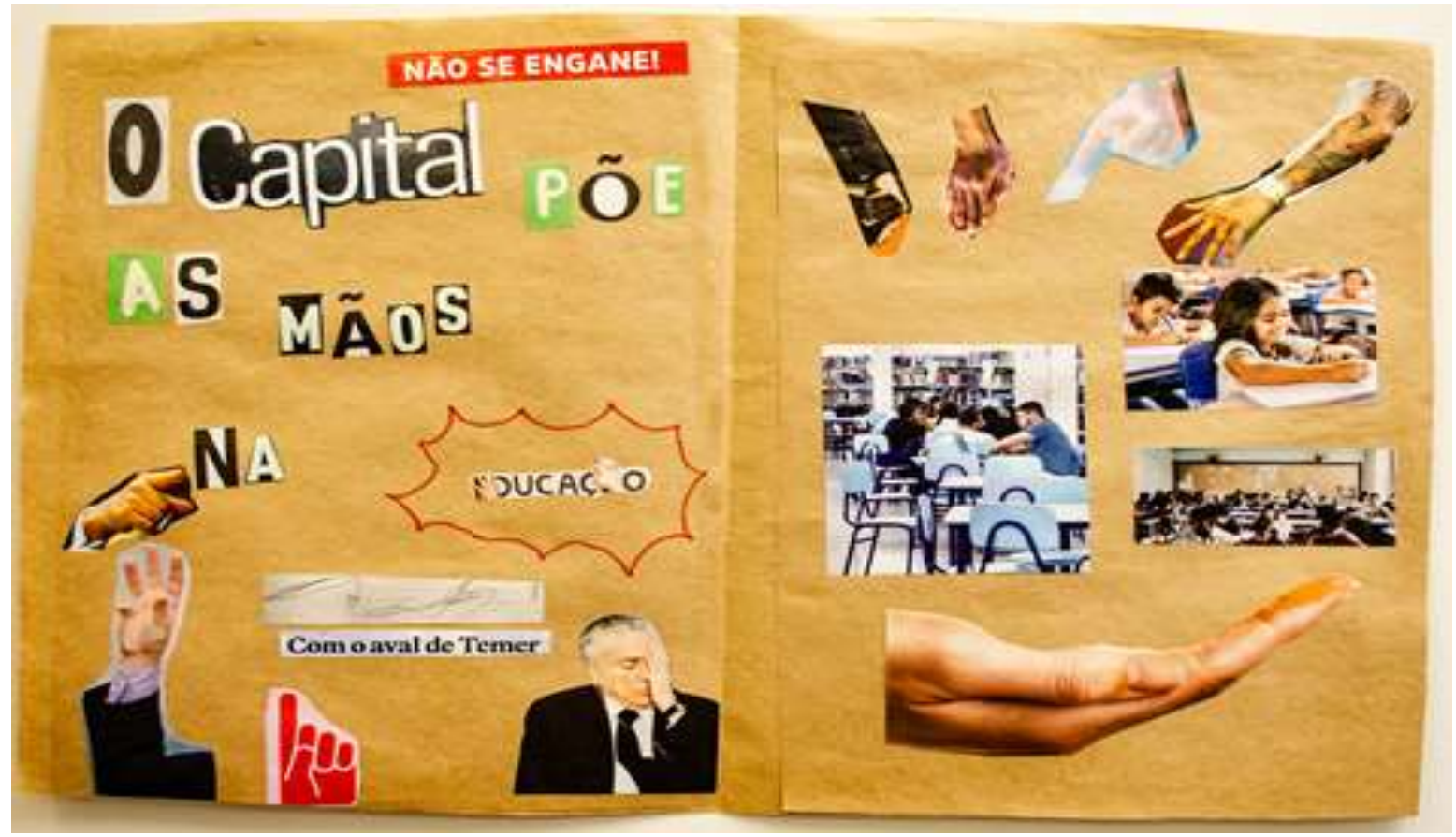

Fonte: Autores (2018).

Essa luta se estende nas décadas seguintes até os dias atuais, acentuando-se no período de redemocratização, com a posse do presidente Fernando Henrique Cardoso (FHC) em 1994, que deu início a uma série de reformas que atingiram diversas áreas sociais, dentre elas a da educação profissional como uma das mais prejudicadas visto que

Após a importante luta social por um projeto de educação unitária, tecnológica e politécnica, visando à formação omnilateral dos trabalhadores e tendo o trabalho como princípio educativo, a educação técnico-profissional de nível médio foi separada mecanicamente do ensino médio e tornada paralela e subsequente a ele (Ciavatta \& Ramos, 2012, p.18).

Desse modo, o discurso que se apresenta como favorável à classe trabalhadora, com uma organização curricular baseada em competências, propondo uma formação que os adaptassem ao trabalho flexível e garantisse empregabilidade, dificulta o acesso de estudantes pobres a uma educação capaz de superar as desigualdades sociais, já que esta separação do ensino médio integrado da educação profissional se contrapõe à educação unitária, que valoriza o trabalho como princípio educativo e a pesquisa como princípio pedagógico.

A seguir, os autores do fanzine destacam que "O capital põe as mãos na educação" e trazem imagens de mãos no canto inferior esquerdo da segunda e em toda a terceira página, que representam empresários e governantes, os quais têm grandes interesses nas reformas que permeiam a educação básica e profissional, em um embate político ideológico como afirma Lemos 
et al. (2017) “em torno de políticas e ações para a concretização da reprodução e ampliação do capital via Estado, que adota uma política educacional a serviço do modelo econômico” (p. 449). Interesses estes que limitam os filhos da classe trabalhadora, representados em três imagens envoltos pelas mãos já mencionadas na terceira página do fanzine, a uma educação centrada no mercado de trabalho, e exclui o caráter humanista e omnilateral de seu currículo formador, situação que favorece grandes grupos econômicos relacionados à educação privada.

Ainda na segunda página do fanzine, a frase "com o aval de Temer" e a imagem do então presidente Michel Temer, que assumiu definitivamente este posto em 31 de agosto de 2016, após a aprovação do processo de impeachment da presidenta Dilma Rousseff, fazem alusão a atual (contra)reforma do ensino médio, consubstanciada na Lei n 13.415 (2017). Esta lei contradiz os projetos anteriores que buscavam, desde o decreto 5.154 (2004), superar a dualidade histórica entre formação geral e profissional e promover à classe trabalhadora uma educação integral, além disso "nega a soberania popular e impõe um ataque às conquistas históricas relativas aos currículos do Ensino Médio, bem como ao financiamento da Educação Básica” (Lemos et al, 2017, p. 456). Já que tal lei, fruto de uma medida provisória (MP) n n 746 (2016), não permitiu um amplo debate da sociedade, com especialistas da área educacional e comunidade escolar, e não prevê investimentos em infraestrutura, formação pedagógica e contratação de profissionais, em uma etapa da escolarização historicamente reconhecida por problemas estruturais e altos índices de evasão.

A crítica presente no fanzine a essa atual reforma, se deve ao fato que, mais uma vez, vive-se no plano educacional, como aponta Ramos (2017), "a violência e o ferimento de morte de um projeto de formação humana voltada para a construção de outra sociedade. Volta-se ao século XIX, quando a classe trabalhadora deveria receber educação somente em doses homeopáticas" (p. 42). Portanto, o projeto que se destina à educação dos trabalhadores representa um ataque ao direito da classe trabalhadora a uma formação emancipatória, capaz de desenvolver o senso crítico e superar o modelo de poder hegemônico que sobrevive às custas da divisão social de classes e do trabalho.

Desse modo, o referido instrumento legal, com ampla divulgação pela mídia e pautado no argumento de que o atual modelo não atende à expectativa dos jovens brasileiros, diminuiu as disciplinas de formação geral, permitirá a deliberada atuação de profissionais de "notório saber" nas disciplinas específicas, e novamente, segundo Lemos et al. (2017) o ensino profissionalizante "assume um caráter de terminalidade não por escolha pessoal, mas por imposição do próprio sistema de ensino, econômico e social vigentes” (p. 458). Sendo que este esvaziamento de conteúdos da formação básica no ensino médio, não só nega o acesso pleno à ciência e à cultura, mas também retira o direito destes estudantes de prosseguirem seus estudos em condições de igualdade com outros que, por condições financeiras superiores, terão acesso às demais áreas do conhecimento.

O primeiro passo para construção de um projeto nacional de educação é a reflexão sobre seu papel transformador para a sociedade. Considerando que o objetivo seja uma sociedade livre das injustiças e de desigualdades sociais, a educação deve ser universal e unitária. A questão da universalidade se relaciona com o acesso amplo à educação pública, gratuita e de qualidade, que deve também ser unitária, rompendo com a lógica dual observada entre o ensino oferecido às elites e aos filhos dos trabalhadores. Em uma sociedade capitalista, pensar a educação é uma atividade de contradição pois, ao mesmo tempo em que se busca oferecer melhores condições de vida à classe trabalhadora por meio da educação, a mesma serve aos interesses do capital quanto à qualificação dos sujeitos que vendem sua força de trabalho (Ramos, 2017).

A divisão dos homens em classes provocou uma divisão a educação, tornando-a espaço potencializador das desigualdades sociais; havendo assim, a partir do escravagismo antigo, uma modalidade de educação para a classe proprietária e outra para a não proprietária. Após a revolução industrial, o acesso à educação escolar foi tornado generalizado por uma necessidade da burguesia, em que era ofertado um patamar mínimo de qualificação geral que garantisse a execução das tarefas de baixa e média complexidade (Saviani, 2007).

A oferta de educação formal, na escola, para todos, não teve como finalidade superar as desigualdades sociais por meio da formação da classe trabalhadora, isso porque a qualidade não acompanhou a expansão da oferta. As máquinas realizariam 
todo o trabalho intelectual enquanto os trabalhadores precisariam apenas de um nível mínimo de educação que permitisse o manuseio delas. Segundo Saviani (2007) "pela maquinaria, que não é outra coisa senão trabalho intelectual materializado, deuse visibilidade ao processo de conversão da ciência, potência espiritual, em potência material” (p. 7).

O processo de educação profissional formal só acontece com o surgimento da eletromecânica, que demanda alguns conhecimentos mais específicos, principalmente no que diz respeito à manutenção do maquinário e à supervisão das atividades. Neste momento, a dualidade educacional já existente se intensifica refletindo a divisão social do trabalho. Os trabalhadores deveriam se formar em cursos profissionalizantes específicos das suas áreas de atuação, enquanto o domínio dos conhecimentos científicos e tecnológicos ficaria reservado às classes dominantes (Saviani, 2007).

Segundo Grabowski e Kuenzer (2016), com a mudança de um regime de acumulação rígida para a acumulação flexível surgiu uma falsa ideia de superação desta dualidade, que foi chamada pelos autores de "dualidade negada". Isso se deve ao fato de que a burguesia usou e distorceu o discurso da universalização da educação e da escola unitária, ao considerar que a partir do momento que não é mais necessário formar um profissional especializado, todos os trabalhadores deveriam receber uma formação geral. Desta forma, têm-se a falsa ideia de que se todos os jovens têm acesso a um mesmo conjunto de conhecimentos, a dualidade educacional estaria superada.

Os autores supracitados trazem ainda a expressão 'dualidade invertida', ao explicar que a formação geral universalmente ofertada não garantiu melhores condições de empregabilidade. Os jovens da classe trabalhadora recebem uma formação meramente certificatória e precária, o que contribui para a manutenção da sociedade de classes. Na prática o objetivo desta formação era o controle dos ânimos dos trabalhadores, que estavam passando por uma transição que precarizou ainda mais suas condições de vida e de trabalho. A ideia de formar um trabalhador multitarefas através de uma formação geral básica possui um viés ideológico. Desta forma, não só a dualidade continua presente de forma estrutural na sociedade e na educação, como intensifica a divisão social do trabalho.

Para a manutenção deste sistema econômico, é essencial que os trabalhadores acreditem que a flexibilidade é benéfica. Este discurso, atrelado ao da meritocracia, culpabiliza os trabalhadores por suas condições de vida, simulando que as condições para a superação dessa divisão social do trabalhador estão dadas e que os trabalhadores não as 'abraçam' como deveriam. Essa ideia equivocada vai ao encontro da Teoria do Capital Humano, a qual, de acordo com Freres, Gomes e Barbosa (2015, p. 75), “" [...] articula trabalho e educação para o desenvolvimento econômico dos países e dos indivíduos (desde que sejam qualificados), ganhando nova configuração e jogando sobre a educação o peso e a responsabilidade pela 'solução' dos problemas gerados pelo capital". 
Figura 3 - Quarta página do fanzine.

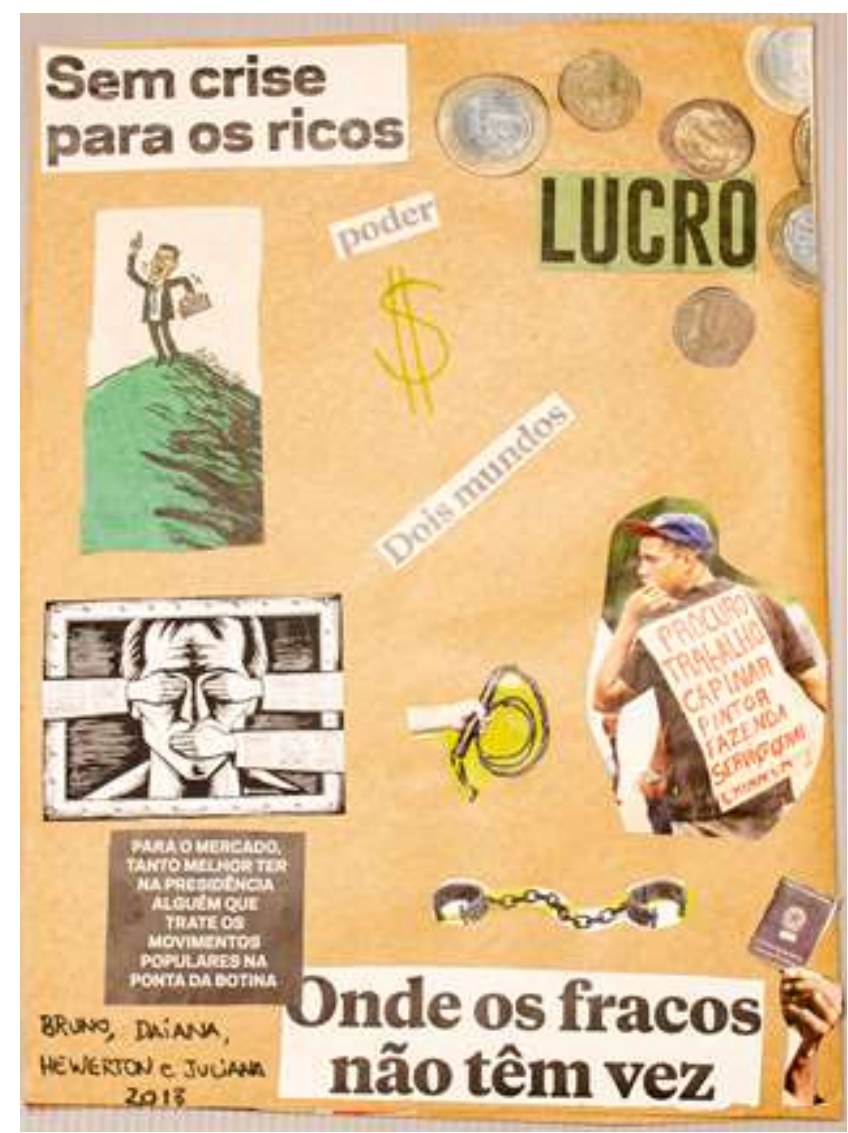

Fonte: Autores (2018).

A quarta página do fanzine, "sem crise para os ricos", representa justamente a divisão social do trabalho e a sociedade de classes. A frase “dois mundos” revela o nível de desigualdade existente, pois, enquanto uma pequena parcela da população vive da exploração da força de trabalho dos demais trabalhadores, estes sofrem com as péssimas condições de vida. Com a afirmação "onde os fracos não têm vez", os autores criticam o discurso da meritocracia e da dualidade negada, o qual culpa os trabalhadores e os responsabilizam por sua empregabilidade, negando a responsabilidade do capital sobre as desigualdades sociais e do desamparo do poder público no que diz respeito a políticas que promovam condições igualitárias.

Retomando o início da seção, a educação pode ser uma forma de transformar a sociedade no sentido de superar as desigualdades e injustiças sociais, mesmo que a escola tenha sido um espaço de reprodução das desigualdades sociais. Para Ramos (2017, p. 9), “ainda que a escola não possa ser considerada o único lócus em que a formação humana aconteça, ela deve ser vista como um espaço privilegiado, uma relevante oportunidade na trajetória de estudantes de diferentes origens sociais, uma alternativa para se construir valores que terão impacto positivo na constituição de uma sociedade mais justa e democrática”.

Ramos (2017) coloca ainda, que o ensino médio é um espaço particularmente potencial, pois sendo a última etapa da educação básica, contempla a parcela da população que ingressará efetivamente no mundo do trabalho. Sendo assim, ao proporcionar um ensino médio de qualidade, gratuito, universal e unitário, seria possível formar cidadãos críticos, conscientes das contradições entre trabalho e capital e que possam agir de forma autônoma na sociedade.

O modelo de ensino politécnico atende às demandas de uma formação integral. A base científica, portanto, não deve ser restrita a conteúdos que fundamentam uma tecnologia específica (por exemplo, o estudo da Física nos cursos de Eletromecânica). É fundamental que as ciências humanas sejam incorporadas na formação do trabalhador com vistas a garantir o currículo integrado (Brasil, 2010).

É importante frisar que politecnia não se remete ao conhecimento de várias técnicas, e sim "trabalha com a perspectiva 
da integração entre trabalho, ciência e a cultura; para a superação da fragmentação do conhecimento, bem como para a construção de saberes significativos e contextualizados à realidade social, econômica e cultural” (Ramos 2017, p. 11). Apesar disso, a autora alerta que há algumas dificuldades objetivas de se construir um projeto politécnico de educação, sendo a principal delas a real necessidade de inserção do estudante no mundo do trabalho durante ou logo após a conclusão do ensino médio. Sendo assim, o ensino médio integrado representa uma possibilidade de travessia entre o modelo dual de educação e um ensino politécnico.

O ensino médio integrado contempla os seguintes sentidos: o da omnilateralidade que se refere à totalidade das dimensões da vida humana e o da integração que remete à indissociabilidade da formação básica e formação profissional e, nessa acepção também, a conexão entre os conhecimentos gerais e os conhecimentos específicos, na perspectiva da totalidade (Ramos, 2017). Nessa perspectiva, Saviani (2007) corrobora com a ideia de que o ensino médio deve proporcionar o conhecimento dos fundamentos que permeiam as diferentes técnicas necessárias à produção, e não apenas a aprendizagem limitada de técnicas produtivas específicas. Contrariando a lógica e desvelando a dualidade negada, o Ensino Médio Integrado propiciará a formação integral dos sujeitos, nas dimensões física, intelectual, cultural, política e afetiva.

\section{Considerações Finais}

Ao analisar a experiência documentada neste artigo, referente à confecção de um fanzine como proposta didática pedagógica na síntese final de uma disciplina de mestrado, percebe-se o potencial deste recurso em explorar a criatividade e a capacidade crítica dos estudantes.

No período proposto para a atividade, os mestrandos foram capazes de confeccionar, refletir e produzir o material, com base em alguns dos textos que serviram de fundamentação na disciplina de Bases Conceituais para a Educação Profissional e Tecnológica, além de abordarem conceitos essenciais à compreensão dos rumos da educação no Brasil e que ficarão documentados por meio deste trabalho.

A produção do fanzine possibilitou aos autores deste artigo a realização de profundas reflexões e a externalização de inquietações sobre o cenário educacional brasileiro, marcado por desigualdades e embates próprios de um campo de disputa, que de um lado quer reduzir as subjetividades da classe trabalhadora aos interesses do capital e, de outro, que luta pelo ideal de escola desinteressada, tal como teorizou Gramsci (2000).

Destaca-se a influência que os organismos internacionais exercem na produção das políticas educacionais dos países da América Latina, dentre eles o Brasil, e a tentativa de disseminar discursos, por intermédio de palavras-chave, nos documentos e leis que regem a educação, e sua ampla difusão entre os educadores. A articulação de variados atores em redes sociais também colabora para a produção e implementação de reformas educacionais que pouco têm passado por consultas públicas, trazendo consigo interesses alheios aos da classe trabalhadora. Além disso, evidencia-se a divisão social de classe e do trabalho que acarreta uma desigualdade profunda e estrutural, pauta-se na competitividade e na culpabilização do trabalhador pela sua situação de desemprego, e nega o acesso a uma educação omnilateral e humanística.

Para reduzir desigualdades e dar oportunidade de uma educação inteira e emancipadora aos filhos da classe trabalhadora, sugere-se, a partir deste estudo, a defesa de uma educação politécnica, sendo aquela "com base no princípio educativo do trabalho, onde está o germe do ensino que poderá elevar a educação da classe operária bastante acima do nível das classes superior e média" (Moura, Lima \& Silva, 2015, p. 1061).

Por fim, a utilização do fanzine como recurso didático poderá contribuir no processo de ensino e aprendizagem, tanto na síntese de conteúdos como foi proposto na atividade analisada, quanto em outras situações didáticas a serem exploradas em diferentes unidades curriculares a fim de integrar conhecimentos do campo da Educação Profissional e Tecnológica e difundir reflexões para um público mais amplo.

Para Demo (2018), a escola possui o desafio de não apenas reproduzir conteúdo e promover sua fixação através de 
provas e avaliações, mas a de “[...] fazer do estudante um autor, cientista, pesquisador” (p. 22). Dessa forma, como sugestão para trabalhos futuros, recomenda-se que o fanzine seja utilizado como ferramenta de aprendizagem com estudantes do Ensino Médio Integrado; uma vez que foi percebido pelos autores deste artigo que esta ferramenta tem o potencial de aguçar a criatividade e estimular a produção autoral dos sujeitos.

\section{Referências}

BRASIL. CNE. Diretrizes curriculares nacionais para a educação profissional técnica de nível médio em debate. Brasília, 2010. de http://portal.mec.gov.br/index.php?option=com_docman\&view=download\&alias=6695-dcn-paraeducacao-profissional-debate\&Itemid=30192

Ciavatta, M. \& Ramos, M. (2012). A Era das Diretrizes: a disputa pelo projeto de educação dos mais pobres. Revista Brasileira de Educação, 17(49), 11-37. http://dx.doi.org/10.1590/S1413-24782012000100002

Decreto $n^{\circ}$ 5.154, de 23 de julho de 2004 (2004). Regulamenta o $\$ 2^{\circ}$ do art. 36 e os arts. 39 a 41 da Lei $n^{\circ} 9.394$, de 20 de dezembro de 1996 , que estabelece as diretrizes e bases da educação nacional, e dá outras providências. Brasília, DF. http://www.planalto.gov.br/ccivil_03/_ato2004-2006/2004/decreto/d5154.htm

Demo, P. (2018). Atividades de aprendizagem: sair da mania do ensino para comprometer-se com a aprendizagem do estudante [recurso eletrônico]. Campo Grande, MS: Secretaria de Estado de Educação do Mato Grosso do Sul - SED/MS. http://www.sed.ms.gov.br/wp-content/uploads/2018/11/eBook-Atividadesde-Aprendizagem-Pedro-Demo.pdf

Freire, P. \& Macedo, D. (1987). Literacy: Reading the word and the world. London: Routledge and Keagan Paul.

Freres, H., Gomes, V. C. \& Barbosa, F. G. (2015). Teoria do capital humano e o reformismo pedagógico pós-1990: fundamentos da educação para o mercado globalizado. In J. Rabelo, S. Jimenez \& M. D. M. Segundo (Orgs.). O movimento de educação para todos e a crítica marxista. (pp. 69-85). Fortaleza: UFC.

Grabowski, G. \& Kuenzer, A. Z. (2016). A produção do conhecimento no campo da Educação Profissional no regime de acumulação flexível. Holos, 6(32), 2232. Recuperado em 12 agosto, 2021, de https://doi.org/10.15628/holos.2016.4983

Gramsci, A. (2000). Cadernos do Cárcere: Os Intelectuais. O Princípio Educativo. Jornalismo (Vol. 2, 8a ed.). Rio de Janeiro: Civilização Brasileira.

Gil, A. C. (2008). Métodos e técnicas de pesquisa social (6a ed.). São Paulo: Atlas.

Lei $n^{\circ} .13 .415$ de 16 de fevereiro de 2017 (2017). (2017, 17 fevereiro). Altera as Leis $n^{\circ}$ 9.394, de 20 de dezembro de 1996 , que estabelece as diretrizes e bases da educação nacional, e 11.494, de 20 de junho 2007, que regulamenta o Fundo de Manutenção e Desenvolvimento da Educação Básica e de Valorização dos Profissionais da Educação, a Consolidação das Leis do Trabalho - CLT, aprovada pelo Decreto-Lei no 5.452, de $1^{\circ}$ de maio de 1943 , e o Decreto-Lei n 236 , de 28 de fevereiro de 1967; revoga a Lei n 11.161 , de 5 de agosto de 2005; e institui a Política de Fomento à Implementação de Escolas de Ensino Médio em Tempo Integral. Brasília, DF. http://www.planalto.gov.br/ccivil_03/_ato2015-2018/2017/lei/113415.htm

Lemos, L. H. G., Silva, M. N., Costa, M. C. F., Lopes, M. V. M. \& Albuquerque, S. L. (2017). A reforma do ensino médio integrado a partir da lei n $13.415 / 2017$ : nova lei - velhos interesses - um recorte histórico a partir do decreto no 2.208/97 aos dias atuais. In A. C. Araújo \& C. N. N. Silva (Orgs.). Ensino médio integrado no Brasil: fundamentos, práticas e desafios. (pp. 449-462). Brasília: Ed. IFB.

Magalhães, H. (1993). O que é fanzine. São Paulo: Brasiliense.

Medida provisória $n^{\circ}$ 746, de 23 de setembro de 2016 (2016). Institui a Política de Fomento à Implementação de Escolas de Ensino Médio em Tempo Integral, altera a Lei $n^{\circ} 9.394$, de 20 de dezembro de 1996, que estabelece as diretrizes e bases da educação nacional, e a Lei $n^{\circ} 11.494$ de 20 de junho 2007 , que regulamenta o Fundo de Manutenção e Desenvolvimento da Educação Básica e de Valorização dos Profissionais da Educação, e dá outras providências. Brasília, DF. https://www.congressonacional.leg.br/materias/medidas-provisorias/-/mpv/126992

Mendes, D. T. (Coord.). (1983). Filosofia da educação brasileira. Rio de Janeiro: Civilização Brasileira.

Moura, D. H. \& Lima, D. L., F. (2017). A reforma do Ensino Médio: regressão de direitos sociais. Retratos da Escola, 11(20), 109-129. Recuperado em 12 agosto, 2021, de https://doi.org/10.22420/rde.v11i20.760

Moura, D. H., Lima, D. L., F. \& Silva, M. R. (2015). Politecnia e formação integrada: confrontos conceituais, projetos políticos e contradições históricas da educação brasileira. Revista Brasileira de Educação, 20(63), 1057-1080. Recuperado em 12 agosto, 2021, de http://dx.doi.org/10.1590/S1413-24782015206313

Ramos, M. N. (2017). Ensino médio integrado: lutas históricas e resistências em tempos de regressão. In A. C. Araújo \& C. N. N. Silva (Orgs.). Ensino médio integrado no Brasil: fundamentos, práticas e desafios. (pp. 20-43). Brasília: Ed. IFB

Resende, V. M. \& Ramalho, V. (2006). Análise de discurso crítica. São Paulo: Contexto.

Saviani, D. (2007). Trabalho e educação: fundamentos ontológicos e históricos. Revista Brasileira de Educação. 12(34), 152-180. http://dx.doi.org/10.1590/S1413-24782007000100012

Shiroma, E. O., Campos, R. F. \& Garcia, R. M. C. (2005). Decifrar textos para compreender a política: subsídios teórico-metodológicos para análise de documentos. Perspectiva, 23(02), 427-446. https://periodicos.ufsc.br/index.php/perspectiva/article/view/9769/8999

Shiroma, E. O. (2011). Redes sociais e hegemonia: apontamentos para estudos de política educacional. In Azevedo, M. L. N. \& Lara, A. M. de B. (Orgs.). Políticas para a educação: análises e apontamentos. (pp. 15-38). Maringá: Eduem. http://gepeto.ced.ufsc.br/files/2015/03/capitulo-eneida.pdf 